\title{
Refractory hypercalcemia: Unusual presentation for diffuse large $B$ cell lymphoma
}

\author{
Dhiraj Yadav*1, Ranjit Kumar Chaudhary ${ }^{2}$, Mohammad Muhsin Chisti ${ }^{3}$ \\ ${ }^{1}$ Department of Internal Medicine, Beaumont Health System, Royal Oak, MI, USA \\ ${ }^{2}$ Institute of Medicine, Kathmandu, Nepal \\ ${ }^{3}$ Department of Hematology and Oncology, Oakland University, William Beaumont School of Medicine, MI, USA
}

Received: February 20, 2016

DOI: $10.5430 /$ crim.v3n3p36
Accepted: June 11, $2016 \quad$ Online Published: June 15, 2016

URL: http://dx.doi.org/10.5430/crim.v3n3p36

\begin{abstract}
Patients with diffuse large B cell lymphoma can occasionally develop hypercalcemia but it is rare at the onset of disease. We present a case of an elderly female who presented with refractory hypercalcemia, workup of which led to the diagnosis of B cell lymphoma. We discuss about various etiologies for development of hypercalcemia in a patient with lymphoma or leukemia.
\end{abstract}

Key Words: Diffuse large B-cell lymphoma, Hypercalcemia, Asymptomatic

\section{BACKGROUND}

Diffuse large B-cell lymphoma (DLBCL) is the most common non-Hodgkin lymphoma (NHL) and constitutes one third of all NHL cases diagnosed annually. ${ }^{[1]}$ Although hypercalcemia is common in adult T-cell lymphoma leukemia, only $1 \%-2 \%$ of patients with lymphoma and leukemia develop hypercalcemia. ${ }^{[2]}$ Patients with DLBCL can occasionally develop hypercalcemia due to various factors but hypercalcemia at onset of disease is uncommon. ${ }^{[3]}$ We present a case of elderly female who presented with refractory hypercalcemia, workup of which led to the diagnosis of DLBCL.

\section{Case presentation}

A 85-year-old female presented to the emergency department with complaints of mild intermittent shortness of breath for last 3 weeks and she was found to have hypercalcemia in routine tests done in her physician's office. She denied having any other symptoms except for constipation. She did not have chest pain, cough, abdominal pain, fever, chills, weight loss or night sweats. She was worked up as an outpatient with 2D echocardiogram and nuclear stress test which were normal. History was significant for atrial fibrillation which was rate controlled with beta blockers, hypertension and myocardial infarction in remote past with placement of stents. She had two back surgeries and bilateral total hip arthroplasty in the past. Family history was not significant for any tumors or hematological malignancies.

On evaluation in EC, her blood pressure was $138 / 88 \mathrm{mmHg}$, pulse of $93 / \mathrm{min}$, respiratory rate of $20 / \mathrm{min}$, normal temperature and saturating in high 90s in room air. Examination was significant for irregular rhythm only. Exam of chest was unremarkable with bilateral clear breath sounds and no wheezing.

\subsection{Investigations}

Laboratory tests revealed white cell count of $5,800 / \mathrm{mm}^{3}$, hemoglobin of $12.1 \mathrm{~g} / \mathrm{dl}$, platelet count of $204,000 / \mathrm{mm}^{3}$ with

*Correspondence: Dhiraj Yadav, MD; Email: dhiraj.yadav@beaumont.edu; Address: Department of Internal Medicine, Beaumont Health System, Royal Oak, MI, USA. 
normal electrolytes, renal and hepatic function tests. However, total calcium level was elevated at $13.8 \mathrm{mg} / \mathrm{dl}$. Ionized calcium was also elevated at $7.95 \mathrm{mg} / \mathrm{dl}$ with $\mathrm{pH}$ of 7.46 . B type natriuretic peptide was high at 1,109 and chest $\mathrm{X}$ ray showed moderate left sided pleural effusion (see Figure 1).

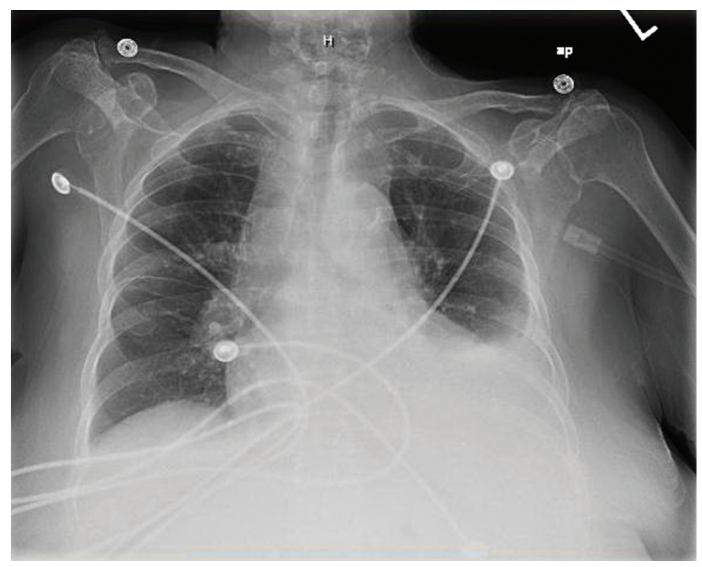

Figure 1. Initial chest $X$ ray showing moderate left sided pleural effusion

On further investigation, parathyroid hormone $(\mathrm{PTH})$ level was suppressed at $4 \mathrm{pg} / \mathrm{ml}$, PTH-related peptide (PTHrP) was normal with value of $1.9 \mathrm{pmol} / \mathrm{L}$. 25 Hydroxy-Vitamin D level was also low at $16 \mathrm{ng} / \mathrm{ml}$, however 1,25 DihydroxyVitamin D was elevated at $125 \mathrm{pg} / \mathrm{ml}$. CT scan of the chest was done which showed extensive soft tissue mass infiltrating throughout the mediastinum obliterating the fat planes between the heart and vascular structures (see Figure 2) with associated neck, axillary and retroperitoneal lymphadenopathy. Bilateral pleural effusion was evident on the CT scan of the chest. Left supraclavicular lymph node was biopsied which revealed an aggressive diffuse large B cell lymphoma with complex karyotype including t $(8 ; 14)$ (q24; q32). Lymphoid cells were confirmed to be B cells through immunohistochemistry and flow cytometry with high proliferation index at 60\%-70\% (flow cytometry showed positive CD20, CD79a, BCL-2, BCL-6 and MUM-1 while CD-10/BCL-1 were negative). Ultrasound guided thoracentesis was also performed and pleural fluid analysis revealed cellular lymphocytic effusion with flow cytometry confirming aberrant B cell population, phenotypically compatible with large B cell lymphoma. PET scan of the body showed multiple increased FDG avid lymphadenopathy above and below the diaphragm and also involving the spleen. Further testing revealed beta 2 microglobulin of $13.09 \mathrm{mg} / \mathrm{L}$ and $\mathrm{LDH}$ of $514 \mathrm{U} / \mathrm{L}$. Bone marrow biopsy was negative for monoclonal plasmacytosis or lymphocytosis. Bone survey did not reveal any osteolytic lesions but serum electrophoresis did show small amount of monoclonal protein $(0.4 \mathrm{~g} / \mathrm{dl})$. Serum levels Published by Sciedu Press of immunoglobulins and free light chains were within normal limits.

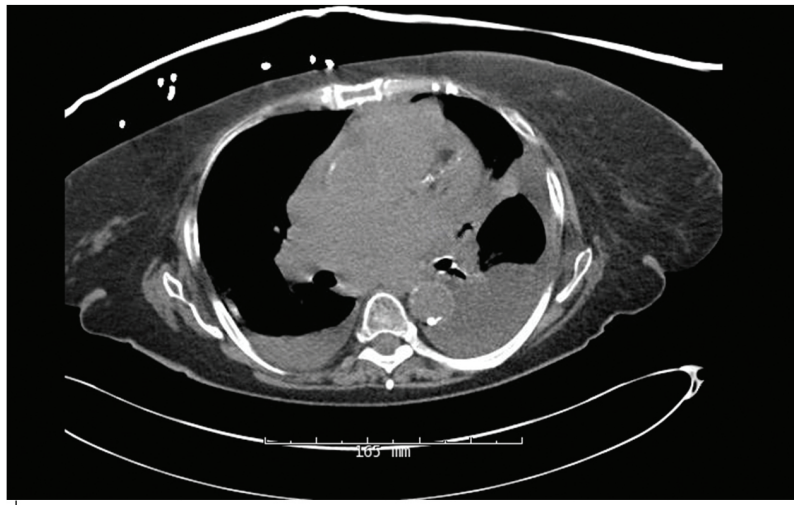

Figure 2. CT scan of the chest showing extensive soft tissue mass infiltrating the mediastinum and bilateral pleural effusions

\subsection{Treatment}

The patient was given diuretics and slow run of intravenous fluids was started for high calcium levels. Calcitonin was also initiated and one dose of pamidronate was given. The patient received multiple doses of calcitonin over the subsequent days along with diuretics and fluids however the calcium level failed to normalize. Ionized calcium was still high at $6.8 \mathrm{mg} / \mathrm{dl}$ before initiation of chemotherapy.

After confirmation of the diagnosis of DLBCL, patient was initiated on attenuated immunochemotherapy regimen (Rmini CHOP: rituximab, doxorubicin, cyclophosphamide, vincristine and prednisone) because of her age and cardiac comorbidities.

CT scan of the chest was repeated after the first cycle of chemotherapy which showed decrease in nodes. She was subsequently started on second cycle of chemotherapy however her hospital course was complicated by pneumonia with severe sepsis, acute deep venous thrombosis and thrombocytopenia.

\subsection{Outcome and follow up}

Unfortunately, the patient passed away a few days after initiation of second cycle of chemotherapy.

\section{Discussion}

Hypercalcemia may be asymptomatic or manifest as arrhythmia, confusion, loss of consciousness, weakness or acute renal failure. ${ }^{[4]}$ Hypercalcemia can result from benign diseases, such as hyperparathyroidism, sarcoidosis, vitamin D toxicosis or due to various types of malignancies including hematological malignancies like multiple myeloma 
and adult T-cell lymphoma leukemia. ${ }^{[5,6]}$ Hypercalcemia associated with malignancy is often symptomatic, occurs in advanced stage and associated with poor prognosis. ${ }^{[7,8]}$ DLBCL is an aggressive B-cell non-Hodgkin's lymphoma that can arise de novo from a mature $\mathrm{B}$ cell or through the transformation of low grade B cell lymphomas like chronic lymphocytic leukemia (Richter's transformation), lymphoplasmacytic lymphoma, follicular lymphoma, marginal zone lymphoma, and splenic marginal zone lymphoma. ${ }^{[9]} \mathrm{Pa}-$ tients with DLBCL typically present with rapidly enlarging mass in lymphatic region which is often asymptomatic and only one third of the patients present with systemic symptoms. Forty percent have extranodal involvement but disseminated extranodal disease is rare. ${ }^{[9]}$ Hypercalcemia can occur occasionally in DLBCL and few cases of DLBCL have been reported to be associated with refractory hypercalcemia ${ }^{[10,11]}$ but hypercalcemia at initial presentation is unusual. ${ }^{[3]}$ There have been few reported cases of hypercalcemia in DLBCL as a result of increased PTHrP which activates osteoclastic bone resorption and release of calcium and phosphate from bone. It occurs via increased osteoblast receptor activator of nuclear factor $\kappa \mathrm{B}$ ligand (RANKL) expression and activation of the receptor activator of nuclear factor $\kappa \mathrm{B}$ (RANK) located on osteoclast precursors. PTHrP also enhances calcium reabsorption in the Loop of Henle and distal convoluted tubule and inhibits phosphate reabsorption in the proximal convoluted tubule but unlike PTH, PTHrP does not increase $1 \alpha$-hydroxylase activity and 1,25 dihydroxyvitamin D3 (1,25- dihydroxycholecalciferol or calcitriol) production. ${ }^{[12,14]}$ Hypercalcemia in DLBCL has also been reported due to increased extrarenal $1 \alpha$-hydroxylase activity in macrophage cells neighboring lymphoma resulting in increased conversion of 25-hydroxyvitamin $\mathrm{D}_{3}$ to 1,25 dihydroxyvitamin $\mathrm{D}_{3}$ which can promote osteoclastic bone resorption and calcium absorption from gut. The extrarenal $1 \alpha$-hydroxylase inhibition by calcitriol is not as effective and result in hypercalcemia. PTH is low with normal 25-hydroxyvitamin and inappropriately high calcitriol while phosphate can be normal or increased. Nephrogenous cAMP, an indicator of activation of renal tubular PTH receptors is low in calcitriol mediated hypercalcemia. ${ }^{[7,15,16]}$ In our case patient had hypercalcemia with normal PTHrP but elevated 1,25-dihydroxycholecalciferol suggesting extrarenal 1- $\alpha$ hydroxylase activity and increased conversion of 25-hydroxycholecalciferol to 1,25-dihydorxycholecalciferol. Occasionally both PTHrP and calcitriol level can increase in patients with DLBCL and both can contribute to hypercalcemia. ${ }^{[17]}$ Besides increased PTHrP and calcitriol, various inflammatory cytokines (Interleukin-6, tumor necrosis factor$\alpha$, etc.) may contribute to hypercalcemia by promoting bone resorption by stimulating proliferation and maturation of osteoclasts. These cytokines interact with RANK on osteoclasts with the RANK ligand on osteoblasts or stromal cells. Moreover, synergistic effect of PTHrP and cytokines on bone resorption can promote hypercalcemia. ${ }^{[2,18]}$ DLBCL can occasionally present with hypercalcemia and multiple osteolytic lesions due to effect of PTHrP and cytokines on bone and may mimic multiple myeloma. ${ }^{[13]}$

Few case studies have reported that new onset of hypercalcemia in a previously indolent B cell lymphoma may indicate Richter's transformation to aggressive form of B-cell lymphoma. ${ }^{[18]}$ Although hypercalcemia has only been occasionally reported with DLBCL, it can be the only presenting feature like in our patient and presence of hypercalcemia in DLBCL may suggest poorer outcome. Larger studies are required to validate this.

\section{Learning points}

- DLBCL can rarely present only with hypercalcemia in otherwise asymptomatic patients and occasionally be an indicator of transformation of low grade hematological malignancies.

- In patients with high level calcium that do not respond well with treatment, possibility of underlying malignancy like DLBCL should be considered even in the absence of other symptoms.

\section{REFERENCES}

[1] Armitage JO, Weisenburger DD. New approach to classifying nonHodgkin's lymphomas: clinical features of the major histologic subtypes. Non-Hodgkin's Lymphoma Classification Project. Journal of Clinical Oncology. 1998; 16(8): 2780-95. PMid:9704731

[2] Nakayama-Ichiyama S, Yokote T, Iwaki K, et al. Hypercalcaemia induced by tumour-derived parathyroid hormone-related protein and multiple cytokines in diffuse large B cell lymphoma, not otherwise specified. Pathology-Journal of the RCPA. 2011; 43(7): 742-5 http://dx.doi.org/10.1097/pat.0b013e32834c83a0

[3] Matsuhashi Y, Tasaka T, Uehara E, et al. Diffuse large B-cell lymphoma presenting with hypercalcemia and multiple osteolysis.
Leukemia \& Lymphoma. 2004; 45(2): 397-400. http: //dx.doi.o $\mathrm{rg} / 10.1080 / 10428190310001593139$

[4] Lindner G, Felber R, Schwarz C, et al. Hypercalcemia in the ED: prevalence, etiology, and outcome. The American Journal of Emergency Medicine. 2013; 31(4): 657-60. PMid:23246111 http://dx.doi.org/10.1016/j.ajem.2012.11.010

[5] Reddi AS. Disorders of Calcium: Hypercalcemia. Fluid, Electrolyte and Acid-Base Disorders. Springer. 2014: 215-31. http: //dx.doi.org/10.1007/978-1-4614-9083-8_19

[6] Endres DB. Investigation of hypercalcemia. Clinical Biochemistry. 2012; 45(12): 954-63. PMid:22569596 http://dx.doi .org/10. 1016/j.clinbiochem.2012.04.025 
[7] Seymour JF, Gagel RF. Calcitriol: the major humoral mediator of hypercalcemia in Hodgkin's disease and non-Hodgkin's lymphomas. Blood. 1993; 82(5): 1383-94. PMid:8364192

[8] Majumdar G. Incidence and prognostic significance of hypercalcaemia in B-cell non-Hodgkin's lymphoma. Journal of Clinical Pathology. 2002; 55(8): 637-8. PMid:12147666 http://dx.doi.o $\mathrm{rg} / 10.1136 / \mathrm{jcp} .55 .8 .637-\mathrm{a}$

[9] Martelli M, Ferreri AJ, Agostinelli C, et al. Diffuse large B-cell lymphoma. Critical Reviews in Oncology/Hematology. 2013; 87(2): 14671. PMid:23375551 http://dx.doi.org/10.1016/j.critrev onc. 2012.12 .009

[10] Ota H, Azuma K, Horiuchi T, et al. An elderly case of non-Hodgkin's lymphoma (NHL) with hypercalcemia. Nihon Ronen Igakkai Zasshi. Japanese Journal of Geriatrics. 2003; 40(2): 167-71. PMid:12708052 http://dx.doi.org/10.3143/geriatrics.40.167

[11] Chou T, Inn H, Wakabayashi M, et al. Successful treatment of nonHodgkin's lymphoma with consciousness disturbance due to hypercalcemia by the calcium-free hemodialysis and combined chemotherapy. The Japanese Journal of Clinical Hematology. 1991; 32(5): 542-7. PMid:1870272

[12] Takasaki H, Kanamori H, Takabayashi M, et al. Non-Hodgkin's lymphoma presenting as multiple bone lesions and hypercalcemia. American Journal of Hematology. 2006; 81(6): 439-42. PMid:16680736 http://dx.doi.org/10.1002/ajh. 20559
[13] Chen P, Li B, Zhuang W, et al. Multiple bone lesions and hypercalcemia presented in diffuse large B cell lymphoma: mimicking multiple myeloma? International Journal of Hematology. 2010; 91(4): 716-22. PMid:20379806 http://dx.doi.org/10.1007/s 12185-010-0562-4

[14] Clines GA. Mechanisms and treatment of hypercalcemia of malignancy. Current Opinion in Endocrinology, Diabetes and Obesity. 2011; 18(6): 339-46. PMid:21897221 http://dx.doi.org/10. 1097 /MED . Ob013e32834b4401

[15] Mudde AH, Berg HVD, Boshuis PG, et al. Ectopic production of 1, 25-dihydroxyvitamin $\mathrm{D}$ by B-cell lymphoma as a cause of hypercalcemia. Cancer. 1987; 59(9): 1543-6. http://dx.doi.org/10.1002/1097-0142(19870501)59: 9<1543: :AID-CNCR2820590902>3.0.CO;2-L

[16] Umlauf D, Bremer A, Baumgärtel M. Ektope Calcitriol-Produktion durch ein Non-Hodgkin-Lymphom als Ursache einer hyperkalzämischen Krise. DMW-Deutsche Medizinische Wochenschrift. 2014; 139(04): 134-8.

[17] Amezyane T, Lecoules S, Bordier L, et al. editors. Humoral hypercalcemia revealing a malignant non hodgkin lymphoma. Annales D'endocrinologie. 2008.

[18] Beaudreuil J, Lortholary O, Martin A, et al. Hypercalcemia may indicate Richter's syndrome. Cancer. 1997; 79(6): 1211 5. http://dx.doi.org/10.1002/(SICI) 1097-0142(199703 15) $79: 6<1211::$ AID-CNCR21>3.0. CO ;2-1 